\title{
Total Antioxidant and Oxidant Status and DPPH Free Radical Activity of Euphorbia eriophora
}

\author{
Hasan Akgül ${ }^{1, a,{ }^{*}}$, Falah Saleh Mohammed ${ }^{2, b}$, Eylem Kına $^{3, \mathrm{c}}$, İmran Uysal ${ }^{4, \mathrm{~d}}$, Mustafa Sevindik, ${ }^{4, e}$, Muhittin Doğan $^{3, \mathrm{f}}$ \\ ${ }^{1}$ Department of Biology, Faculty of Science, Akdeniz University, 07525 Antalya, Turkey \\ ${ }^{2}$ Department of Biology, Faculty of Science, Zakho University, Zakho, Iraq \\ ${ }^{3}$ Department of Biology, Faculty of Science and Literature, Gaziantep University, 27410 Gaziantep, Turkey \\ ${ }^{4}$ Department of Food Processing, Bahçe Vocational School, Osmaniye Korkut Ata University, 80010 Osmaniye, Turkey \\ *Corresponding author
}

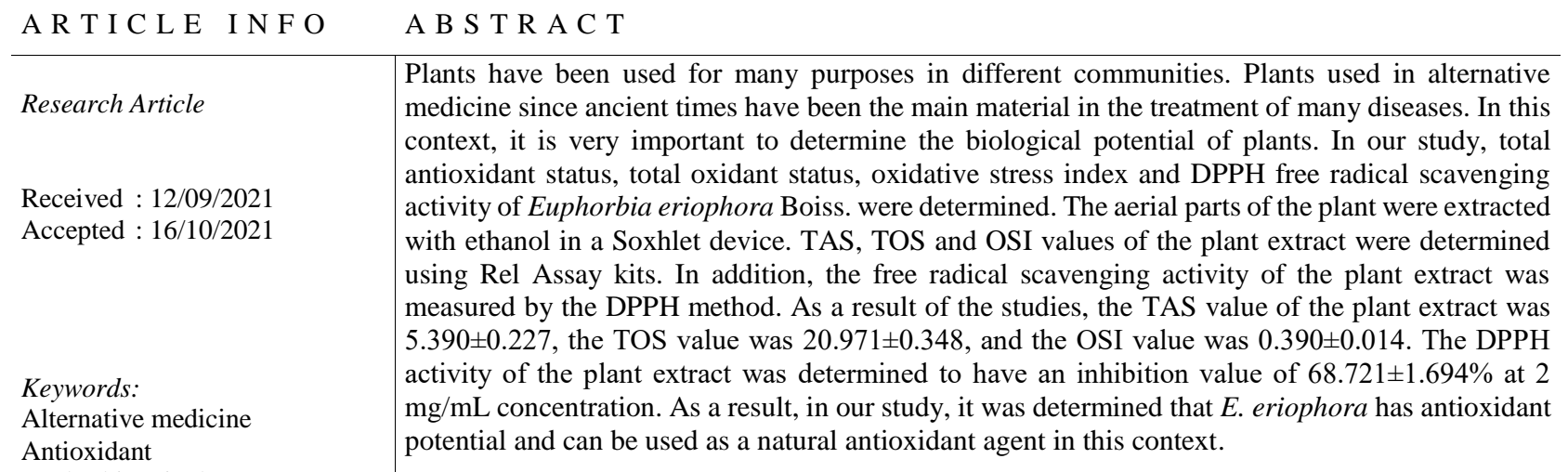

Euphorbia eriophora

Oxidant

Medicinal plants

hakgul@akdeniz.edu.tr eylem.kinaa@gmail.com

sevindik27@gmail.com
(D) http://orcid.org/0000-0001-8514-9776
(iD) http://orcid.org/0000-0003-4538-9737
(iD) http://orcid.org/0000-0001-7223-2220

falah.sindy@uoz.edu.krd uysal-imran@hotmail.com doganm@gantep.edu.tr http://orcid.org/0000-0001-9083-1876 http://orcid.org/0000-0003-4538-9737 http://orcid.org/0000-0001-5400-8065

\section{Introduction}

Complementary medicine is widely used in the treatment of diseases in many societies. Many natural materials are used in complementary medicine in different parts of the world (Popović et al., 2016). Plants, fungi and animals are natural materials that are widely used, especially in developing countries (Dorai et al., 2012). In particular, plants contain active ingredients used in the production of many drugs (Chang and Lu, 2009; Diaz et al., 2012). Thanks to these active substances produced by plants, they have anticancer, antimicrobial, DNA protective activity, antioxidant, antiproliferative and anti-inflammatory activities (Trouillas et al., 2003; Dai and Mumper, 2010; Talib and Mahasneh, 2010; Mohammed et al., 2018; Sevindik, 2018; Salehi et al., 2019; Salehi et al., 2019). For this reason, the discovery of plants with biological activity is very important in terms of complementary medicine.
Compounds with antioxidant properties are found in many plants. These plants play an important role in reducing the effects of harmful levels of oxidant compounds (Bobrovskikh et al., 2020; Ivanišová et al., 2021). In this context, it is important to investigate plants with antioxidant effects. In this study, E. eriophora (Euphorbiaceae) was used as the material. Euphorbiaceae is a family represented by 300 genera and 5000 species worldwide. Different Euphorbia species are used in the treatment of skin diseases, gonorrhea, migraine, intestinal parasites in many different parts of the world. Euphorbia members spread cosmopolitanly in many parts of the world. These species contain many phytochemical compounds (Yener et al., 2018). In our study, total antioxidant, total oxidant status and DPPH free radical scavenging activity of aerial parts of $E$. eriophora plant were determined. 
Table 1. TAS, TOS and OSI values of Euphorbia eriophora extract

\begin{tabular}{l|ll} 
Sample & TAS $(\mathrm{mmol} / \mathrm{L}) \mathrm{TOS}(\mu \mathrm{mol} / \mathrm{L})$ & OSI \\
\hline
\end{tabular}

\begin{tabular}{l|rrrr}
\hline E. eriophora & $5.390 \pm 0.227$ & $20.971 \pm 0.348$ & $0.390 \pm 0.014$ \\
\hline Varese
\end{tabular}

Values are presented as mean \pm S.D

Table 2. DPPH free radical activity of Euphorbia eriophora extract

\begin{tabular}{|c|c|c|}
\hline Concentration & Ascorbic & $\mathrm{EtOH}$ \\
\hline$(\mathrm{mg} / \mathrm{mL})$ & acid (\%) & Livi \\
\hline 0.25 & $68.500 \pm 1.724$ & $28.311 \pm 1.554$ \\
\hline 0.5 & $92.718 \pm 1.544$ & $45.683 \pm 1.413$ \\
\hline 1 & $94.424 \pm 0.537$ & $57.355 \pm 2.076$ \\
\hline 2 & $96.388 \pm 0.670$ & $68.721 \pm 1.694$ \\
\hline
\end{tabular}

\section{Materials and Methods}

Plant samples were collected from Gaziantep (Turkey) and their identifications were made using Flora of Turkey Volume 7 (page: 595). The aerial parts of the plant were dried under suitable conditions. After drying, the samples were ground into powder. $30 \mathrm{~g}$ of the samples were weighed and placed in cartridges and extracted with ethanol at $50{ }^{\circ} \mathrm{C}$ for about 6 hours in a Soxhlet device. Then, solvents were removed from the obtained extracts.

\section{Antioxidant Activity}

Total antioxidant (TAS), total oxidant status (TOS) and oxidative stress index of EtOH extract of the plant were measured using Rel Assay TAS, TOS kits (Erel, 2004; Erel 2005). Trolox was used as the calibrator in the TAS kits and the results were expressed as mmol Trolox equiv./L. Hydrogen peroxide was used as calibrator in TOS kits and the results were expressed as $\mu \mathrm{mol} \mathrm{H}_{2} \mathrm{O}_{2}$ equiv./L. Oxidative stress index (OSI) was determined by dividing the unit of TOS value to the unit of TAS value (Sevindik, 2019).

Stock solutions were prepared from plant extracts using DMSO (Dimethyl sulfoxide) at $0.25,0.5,1$ and $2 \mathrm{mg} / \mathrm{mL}$ concentrations. $50 \mu \mathrm{L}$ of the stock solutions were added to $160 \mu \mathrm{L}$ of $0.039 \% \mathrm{DPPH}$ and incubated for 30 minutes. After incubation, absorbance was determined at $517 \mathrm{~nm}$. These processes were repeated at all concentrations of the plant extracts (Shimada et al., 1992). Ascorbic acid (AA) was used as the reference antioxidant.

\section{Result and Discussion}

In recent years, the discovery of plants with antioxidant properties has increased. Antioxidant compounds play a role in reducing the effect of oxidative stress (Hoseinifar et al., 2020; Islek et al., 2021). There is an increase in the levels of oxidant compounds produced as a result of environmental and structural effects and metabolic activities of the organism. In this case, the antioxidant defense system comes into play in reducing the effect of oxidant compounds (Korkmaz et al., 2018; Forman and Zhang, 2021). When the antioxidant defense system is insufficient, oxidative stress occurs. As a result of oxidative stress, many diseases such as Parkinson's, Alzheimer's, cardiological disorders and cancer can occur in humans. Supplemental antioxidants are very important in reducing the effects of oxidative stress (Dubois-Deruy et al., 2020; Sevindik et al., 2020; Sarıdogan et al., 2021). In this context, it is very important to investigate the antioxidant properties of plants. In this study, TAS, TOS and OSI values of E. eriophora were determined. The obtained results are shown in Table 1. In addition, DPPH free radical scavenging activities of plant extracts are shown in Table 2.

In this study, TAS, TOS and OSI values of EtOH extract of E. eriophora were determined using Rel Assay kits. In addition, the DPPH free radical scavenging activity of the plant extracts was determined. No study has been found to determine the TAS, TOS and OSI values of $E$. eriophora before. In a previous study, the antioxidant activity of methanol extracts of E. eriophora was investigated by $\beta$-Carotene-linoleic acid test system, DPPH free radical and ABTS cation radical scavenging and cupric reducing antioxidant capacity (CUPRAC) methods. As a result of the study, it was reported to have high antioxidant activities (Yener et al., 2018). In our study, EtOH extract of the plant was used and its effects were investigated at $0.25,0.5,1$ and $2 \mathrm{mg} / \mathrm{mL}$ concentrations. As a result of the study, it was observed that DPPH activity increased as the concentration of plant extracts increased. The highest activity was measured as $68.721 \pm 1.694$ at $2 \mathrm{mg} / \mathrm{mL}$ from the test concentrations. The percent inhibition concentration of Ascorbic acid, the standard used, was measured as $96.388 \pm 0.670$ at $2 \mathrm{mg} / \mathrm{mL}$. It is seen that the DPPH activity of the plant extract at the same concentration is lower than the standard used. However, it was determined that the plant has DPPH activity. In this context, Yener et al., (2018) concluded that the findings we obtained are similar to their study, and that there is DPPH activity. As a result, it was determined that E. eriophora has antioxidant potential.

TAS values show all of the antioxidant compounds in the plant (Mohammed et al., 2019). In our study, TAS values of E. eriophora were determined for the first time. In previous TAS studies on different plants, Mentha longifolia subsp. longifolia (TAS: 3.628), Marrubium globosum (TAS: 7.677), Datura stramonium (TAS: 7.559), Thymbra spicata (TAS: 8.399), Rosa canina (TAS: 4.602), Scorzonera papposa (TAS: 5.314), Salvia absconditiflora (TAS: 6.979), Salvia multicaulis (TAS: 6.434), Rumex crispus (TAS: 6.758) and Gundellia tournefortii (TAS: 6.831) have been reported (Sevindik et al., 2017; Pehlivan and Sevindik, 2018; Pehlivan et al., 2018; Daştan et al., 2019; Saraç et al., 2019; Akgül et al., 2020; Mohammed et al., 2020a; Mohammed et al., 2020b; Mohammed et al. ., 2021; Pehlivan et al., 2021). Compared to these studies, the TAS value of E. eriophora was higher than M. longifolia subsp. longifolia, $R$. canina and S. papposa, and lower than M. globosum, D. stramonium, $T$. spicata, $S$. absconditiflora, $S$. multicaulis, $R$. crispus and $G$. tournefortii. As seen in our study, it was determined that $E$. eriophora has antioxidant potential. It is thought that the antioxidant effective compounds in the body of $E$. eriophora can be determined and used as an antioxidant source with future studies.

TOS value shows the whole of the oxidant compounds produced by the plant as a result of environmental and structural effects and metabolic activities (Mohammed et al., 2019). In previous TOS studies on different plants, $M$. 
longifolia subsp. longifolia (TOS: 4.046), M. globosum (TOS: 12.387), D. stramonium (TOS: 10.711), T. spicata (TOS: 6.530), R. canina (TOS: 6.294), S. papposa (TOS: 24.199), S. absconditiflora (TOS: 5.681), S. multicaulis (TAS: 22.441), R. crispus (TOS: 5.802) and G. tournefortii (TOS: 3.712) have been reported (Sevindik et al., 2017; Pehlivan and Sevindik, 2018; Pehlivan et al., 2018; Daştan et al., 2019; Saraç et al., 2019; Akgül et al., 2020; Mohammed et al., 2020a; Mohammed et al., 2020b; Mohammed et al., 2021; Pehlivan et al., 2021). Compared to these studies, the TOS value of E. eriophora was lower than S. multicaulis and S. papposa, and higher than $M$. longifolia subsp. longifolia, M. globosum, D. stramonium, $T$. spicata, R. canina, S. absconditiflora, $R$. crispus and $G$. tournefortii. In this context, it has been determined that $E$. eriophora has high oxidant values by taking the plants mentioned in the literature as standard.

The OSI value shows how much the plant suppresses the oxidant compounds produced in the plant with endogenous antioxidants. High OSI value indicates that the plant's defense system is insufficient against oxidant compounds (Mohammed et al., 2019). In previous OSI studies on different plants, M. longifolia subsp. longifolia (OSI: 0.112), M. globosum (OSI: 0.162), D. stramonium (OSI: 0.142), T. spicata (OSI: 0.078), R. canina (OSI: $0.138)$, S. papposa (OSI: 0.456), S. absconditiflora (OSI: 0.081), S. multicaulis (TAS: 0.349), R. crispus (OSI: 0.086), and G. tournefortii (OSI: 0.054) have been reported (Sevindik et al., 2017; Pehlivan and Sevindik, 2018; Pehlivan et al., 2018; Daştan et al., 2019; Saraç et al., 2019; Akgül et al., 2020; Mohammed et al., 2020a; Mohammed et al., 2020b; Mohammed et al., 2021; Pehlivan et al., 2021). Compared to these studies, the OSI value of $E$. eriophora was lower than S. papposa and higher than $M$. longifolia subsp. longifolia, M. globosum, D. stramonium, T. spicata, R. canina, S. absconditiflora, S. multicaulis, $R$. crispus, G. tournefortii. In this context, it is seen that the oxidant compounds produced by E. eriophora are insufficient in suppressing with the antioxidant defense system.

\section{Conclusion}

In this study, the antioxidant potential of E. eriophora, one of the plants used in alternative medicine, was determined for the first time with Rel Assay kits. In addition, the DPPH free radical scavenging activity of the plant was determined. As a result of the studies, it was determined that E. eriophora has antioxidant potential.

\section{References}

Alfei S, Marengo B, Zuccari G. 2020. Oxidative stress, antioxidant capabilities, and bioavailability: Ellagic acid or urolithins? Antioxidants, 9(8):707.

Akgul H, Korkmaz N, Dayangaç A, Sevindik M. 2020. Antioxidant Potential of Endemic Salvia absconditiflora. Turkish Journal of Agriculture-Food Science and Technology, 8(10): 2222-2224.

Baharum Z, Akim AM, Taufiq-Yap YH, Hamid RA, Kasran R. 2014. In vitro antioxidant and antiproliferative activities of methanolic plant part extracts of Theobroma cacao. Molecules, 19(11): 18317-18331.

Bobrovskikh A, Zubairova U, Kolodkin A, Doroshkov A. 2020. Subcellular compartmentalization of the plant antioxidant system: an integrated overview. PeerJ, 8: e9451.
Chang FY, Lu CL. 2009. Treatment of irritable bowel syndrome using complementary and alternative medicine. Journal of the Chinese Medical Association, 72(6): 294-300.

Dai J, Mumper RJ. 2010. Plant phenolics: extraction, analysis and their antioxidant and anticancer properties. Molecules, 15(10): 7313-7352.

Daştan SD, Durukan H, Demirbaş A, Dönmez E. 2019. Bioactivity and Therapeutic Properties of Evelik (Rumex crispus), A Naturally Growing and Edible Plant in Sivas Province. Turkish Journal of Agriculture-Food Science and Technology, 7(sp2): 67-71.

Davis PH. 1982. Flora of Turkey and the East Aegean Islands. Vol. 7. Edinburgh University Press, Edinburgh, UK

Dorai AA. 2012. Wound care with traditional, complementary and alternative medicine. Indian Journal of plastic surgery, 45(02): 418-424.

Diaz LA, Torregrosa L, Benítez L, Mercado M, Fiorentino S. 2012. Plant-based Complementary and alternative medicine used by breast cancer patients at the Hospital Universitario San Ignacio in Bogotá, Colombia. Universitas Scientiarum, 17(3): 291-302.

Dubois-Deruy E, Peugnet V, Turkieh A, Pinet F. 2020. Oxidative stress in cardiovascular diseases. Antioxidants, 9(9): 864.

Erel O. 2004. A novel automated direct measurement method for total antioxidant capacity using a new generation, more stable ABTS radical cation. Clinical biochemistry, 37(4): 277-285.

Erel O. 2005. A new automated colorimetric method for measuring total oxidant status. Clinical biochemistry, 38(12): 1103-1111.

Forman HJ, Zhang H. 2021. Targeting oxidative stress in disease: Promise and limitations of antioxidant therapy. Nature Reviews Drug Discovery, 1-21.

Hoseinifar SH, Yousefi S, Van Doan H, Ashouri G, Gioacchini G, Maradonna F, Carnevali O. 2020. Oxidative stress and antioxidant defense in fish: The implications of probiotic, prebiotic, and synbiotics. Reviews in Fisheries Science \& Aquaculture, 29(2): 198-217.

Islek C, Saridogan BGO, Sevindik M, Akata I. 2021. Biological Activities and Heavy Metal Contents of Some Pholiota Species. Fresenius Environmental Bulletin, 30(6): 6109-6114

Ivanišová E, Tokár $\mathrm{M}$, Mocko $\mathrm{K}$, Bojňanská $\mathrm{T}$, Mareček J, Mendelová A. 2021. Antioxidant activity of selected plant products. Journal of Microbiology, Biotechnology and Food Sciences, 2021: 1692-1703.

Korkmaz AI, Akgul H, Sevindik M, Selamoglu Z. 2018. Study on determination of bioactive potentials of certain lichens. Acta Alimentaria, 47(1): 80-87.

Mohammed FS, Akgul H, Sevindik M, Khaled BMT. 2018. Phenolic content and biological activities of Rhus coriaria var. zebaria. Fresenius Environmental Bulletin, 27(8): 5694-5702.

Mohammed FS, Pehlivan M, Sevindik M. 2019. Antioxidant, antibacterial and antifungal activities of different extracts of Silybum marianum collected from Duhok (Iraq). International Journal of Secondary Metabolite, 6(4): 317-322.

Mohammed FS, Günal S, Şabik AE, Akgül H, Sevindik M. 2020a. Antioxidant and Antimicrobial activity of Scorzonera papposa collected from Iraq and Turkey. Kahramanmaraş Sütçü İmam Üniversitesi Tarım ve Doğa Dergisi, 23(5): 1114-1118.

Mohammed FS, Kına E, Sevindik M, Dogan M, Pehlivan M. 2021. Datura stramonium (Solanaceae): Antioxidant and Antimicrobial Potentials. Turkish Journal of Agriculture-Food Science and Technology, 9(4): 818-821.

Mohammed FS, Şabik AE, Sevindik E, Pehlivan M, Sevindik M. 2020b. Determination of Antioxidant and Oxidant Potentials of Thymbra spicata Collected from Duhok-Iraq. Turkish Journal of Agriculture-Food Science and Technology, 8(5): 1171-1173.

Pehlivan M, Sevindik M. 2018. Antioxidant and antimicrobial activities of Salvia multicaulis. Turkish Journal of Agriculture-Food Science and Technology, 6(5): 628-631.

Pehlivan M, Mohammed FS, Sevindik M, Akgul H. 2018. Antioxidant and oxidant potential of Rosa canina. Eurasian Journal of Forest Science, 6(4): 22-25. 
Pehlivan M, Mohammed FS, Şabik AE, Kına E, Dogan M, Yumrutaş Ö, Sevindik M. 2021. Some Biological activities of ethanol extract of Marrubium globosum. Turkish Journal of Agriculture-Food Science and Technology, 9(6): 1129-1132.

Popović Z, Matić R, Bojović S, Stefanović M, Vidaković V. 2016. Ethnobotany and herbal medicine in modern complementary and alternative medicine: An overview of publications in the field of I\&C medicine 2001-2013. Journal of ethnopharmacology, 181: 182-192.

Salehi B, Gültekin-Özgüven M, Kırkın C, Özçelik B, MoraisBraga MFB, Carneiro JNP, Bezerra CF, da Silva TG, Coutinho HDM, Amina B, Armstrong L, Selamoglu Z, Sevindik M, Yousaf Z, Sharifi-Rad J, Muddathir AM, Devkota HP, Martorell M, Jugran AK, Martins N, Cho WC. 2019. Anacardium plants: chemical, nutritional composition and biotechnological applications. Biomolecules, 9(9): 465.

Salehi B, Gültekin-Özgüven M, Kirkin C, Özçelik B, MoraisBraga MFB, Carneiro JNP, Bezerra CF, da Silva TG, Coutinho HDM, Amina B, Armstrong L, Selamoglu Z, Sevindik M, Yousaf Z, Sharifi-Rad J, Muddathir AM, Devkota HP, Martorell M, Jugran AK, Cho W, Martins N. 2020. Antioxidant, antimicrobial, and anticancer effects of anacardium plants: an ethnopharmacological perspective. Frontiers in Endocrinology, 11: 295.

Saraç H, Demirbaş A, Daştan SD, Ataş M, Çevik Ö, Eruygur N. 2019. Evaluation of Nutrients and Biological Activities of Kenger (Gundellia tournefortii L.) Seeds Cultivated in Sivas Province. Turkish Journal of Agriculture-Food Science and Technology, 7(sp2): 52-58.

Saridogan BGO, Islek C, Baba H, Akata I, Sevindik M. 2021. Antioxidant Antimicrobial Oxidant and Elements Contents of Xylaria polymorpha and X. hypoxylon (Xylariaceae). Fresenius Environmental Bulletin, 30(5): 5400-5404

Sevindik M. 2018. Pharmacological properties of Mentha species. J Tradit Med Clin Natur, 7(2): 259.
Sevindik M, Akgul H, Pehlivan M, Selamoglu Z. 2017. Determination of therapeutic potential of Mentha longifolia ssp. longifolia. Fresenius Environmental Bulletin, 26(7): 4757-4763.

Sevindik M. 2019. Wild edible mushroom Cantharellus cibarius as a natural antioxidant food. Turkish Journal of AgricultureFood Science and Technology, 7(9): 1377-1381.

Sevindik M, Akgul H, Selamoglu Z, Braidy N. 2020. Antioxidant and antigenotoxic potential of Infundibulicybe geotropa mushroom collected from Northwestern Turkey. Oxidative medicine and cellular longevity, 2020.

Shahbazi R, Sharifzad F, Bagheri R, Alsadi N, Yasavoli-Sharahi H, Matar C. 2021. Anti-Inflammatory and Immunomodulatory Properties of Fermented Plant Foods. Nutrients, 13(5): 1516.

Shimada K, Fujikawa K, Yahara K, Nakamura T. 1992. Antioxidative properties of xanthan on the autoxidation of soybean oil in cyclodextrin emulsion. Journal of agricultural and food chemistry, 40(6): 945-948.

Talib WH, Mahasneh AM. 2010. Antiproliferative activity of plant extracts used against cancer in traditional medicine. Scientia pharmaceutica, 78(1): 33-46.

Trouillas P, Calliste CA, Allais DP, Simon A, Marfak A, Delage C, Duroux JL. 2003. Antioxidant, anti-inflammatory and antiproliferative properties of sixteen water plant extracts used in the Limousin countryside as herbal teas. Food chemistry, 80(3): 399-407.

Yener İ, Ölmez ÖT, Ertas A, Yilmaz MA, Firat M, Kandemir Sİ, Öztürk M, Kolak U, Temel H. 2018. A detailed study on chemical and biological profile of nine Euphorbia species from Turkey with chemometric approach: Remarkable cytotoxicity of E. fistulasa and promising tannic acid content of E. eriophora. Industrial Crops and Products, 123: 442-453. 